\title{
A modeling framework to evaluate climate change and watershed development impacts on water security
}

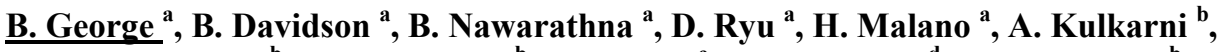 \\ S. Patwardhan ${ }^{b}$, N. Deshpande ${ }^{\text {b }}$, P. Pavelic ${ }^{\text {c }}$, J. Anshuman ${ }^{\text {d }}$ and K. Kumar ${ }^{b}$ \\ ${ }^{a}$ Department of Infrastructure Engineering, The University of Melbourne, Parkville, VIC, 3010 \\ ${ }^{b}$ Indian Institute of Tropical Meteorology, Pune, India \\ ${ }^{c}$ International Water Management Institute, Patancheru, Hyderabad, India \\ ${ }^{d}$ The Energy Resources Institute, New Delhi, India
}

Email: biju@unimelb.edu.au

\begin{abstract}
The long-term impacts of climate change on water resources are expected to be considerable in many parts of the globe. Resulting hydrologic changes can have a high impact on river basins like Krishna, India and Murray Darling, Australia where severe competition of water between stakeholders and states exists. Australia is already experiencing significant impacts of climate change: the average surface air temperatures have increased by $0.9^{\circ} \mathrm{C}$ since 1950 and precipitation has declined along the east and west coasts of the country. Analysis of emission scenarios suggests that warming of between $1{ }^{\circ} \mathrm{C}$ and $2.5^{\circ} \mathrm{C}$ is likely by 2070 if emissions are low and between $2^{\circ} \mathrm{C}$ and $5^{\circ} \mathrm{C}$ under a high emission scenario.
\end{abstract}

In India climate change possess challenges due to its vast geographic diversity. The projections for the country suggests that some regions will experience more intense rainfall and flood risks while other areas are going to get sparse rainfall and prolonged droughts. Accordingly, runoff is predicted to vary both spatially and temporally. Watershed Development (WSD) programs in rain-fed dry land agriculture in India have been introduced to ensure the sustainability of the surface and groundwater resources by harvesting rainwater, and to improve the livelihoods of farmers. A number of artificial water storage and diversion structures were established in the last few decades under this program. This will further intensify the problem by reducing the inflow into the reservoirs. This paper presents an integrated conceptual framework to assess impacts of climate change and WSD impacts on water security and to assess response strategies to cope with the combined impacts.

The framework used in this study involves the integration of biophysical and hydrological modelling coupled with socio-economic modelling to provide a quantitative hydro-economic evaluation of the performance associated with each scenario-response combination. In this research, results from a general circulation model (GCM) are downscaled to the sub-basin level to generate input forcing information adapted to run a regional hydrological model on the future climate scenarios. In order to assess the climate change impacts on hydrological cycle, a fully distributed surface and groundwater modelling is proposed. The impact of watershed development on hydrology will also be analysed using this modelling framework. An integrated water allocation-economic modelling will be carried out to assess the water security and its economic value. Finally, the modelling framework will be used to evaluate a range of scientifically defensible social and economic policies driven by stakeholders, rather than seeking a single preferred (optimal) alternative.

The conceptual framework presented in this paper is designed to respond to future climate change within a whole of river basin approach. The framework will be applied in the Musi catchment in Andhra Pradesh, India, designed to examine water security strategies under climate change.

Keywords: Climate change, Krishna Basin, hydrology 
George et al., A modelling framework to evaluate climate change and watershed development impacts

\section{INTRODUCTION}

Human activities since the beginning of the industrial revolution are increasing the atmosphere concentration of greenhouse gases, which alter radiative balances and tend to warm atmosphere (Kumar et al. 2006). In some other regions aerosols have an opposite effect and tend to cool atmosphere. Such projected changes in GHG and aerosols lead to changes in climate variables like temperature and rainfall which results in large changes in runoff.

The spatial and temporal variability of rainfall in India is extreme. India gets most of its water during SouthWest Monsoon period (June-September) leaving remaining months dry. Therefore application of irrigation water to supplement natural rainfall is frequently needed so as to guarantee reliable crop yields. Use of surface water for irrigation in India is a centuries old practice. But soon after independence the Government of India took major steps to harness surface water for agriculture through Five Year Plans. After 1970 and up until 1995, groundwater irrigation development in India grew rapidly. Farmers and entrepreneurs in the country invested approximately \$US12 billion in groundwater irrigation. More than 19 million diesel or electric pumps are now employed to extract water from irrigation wells (Shah et al. 2007).

Watershed Development (WSD) programs in rain-fed dry land agriculture in India have been introduced to ensure the sustainability of the surface and groundwater resources by harvesting rainwater, and to improve the livelihoods of farmers. These programs have been applied at the micro-catchment level (up to 500 hectares). Under this programme the number of artificial water storage and diversion structures for storing runoff has exponentially increased during the last few decades. However there is little information on the hydrological impacts at the local and catchment scale. The impacts of increasing hydrological structures on downstream users is unknown and is an important issue for planning water resources at the basin scale (George et al. 2011).

Climate change is expected to have a significant impact on water security. This is also expected to be exacerbated by increased variability in inflows arising from WSD. The allocation of water to various users requires knowledge of hydrology and the social and institutional governance mechanisms to support the necessary adaptive changes. The main aim in this paper is to present a methodology to assess the combined impacts of watershed development and climate change on the long term water security for agriculture in the Krishna river basin, India and develop and test adaptation scenarios.

\section{THE STUDY AREA}

The Krishna Basin is the fourth largest river basin in India in terms of annual discharge (at $65 \mathrm{~km}^{3}$ ) and the fifth largest in terms of surface area (at 258,948 $\mathrm{km}^{2}$ ). The basin traverses through three large states - Karnataka, Maharashtra and Andhra Pradesh (Figure 1). The river supplies 73 million people with their water needs. This basin is interesting as it is nearly closed, crosses jurisdictional boundaries, experiences both spatial and sectorial demand pressures for more water and suffers from a number of environmental pressures. The acute water shortages in the basin are leading to interstate conflicts on the allocation and use of the resource.

Detailed analysis of watershed development will be carried out in the Musi catchment, a principle tributary of the Krishna River in India. The Musi River catchment supports a population of around

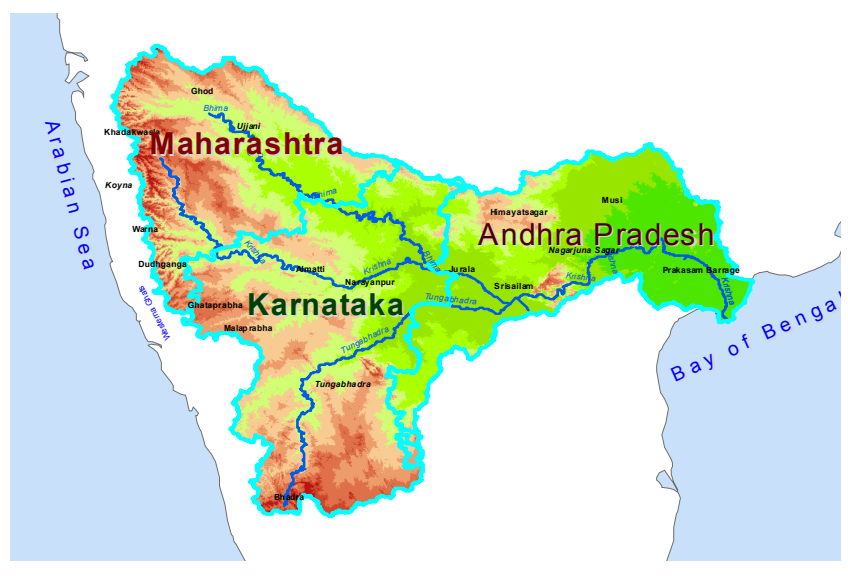

Figure 1. Map of Krishna Basin. 10 million people in an area of approximately $11,000 \mathrm{~km}^{2}$. The climate of the Musi sub-basin is typical of the semi-arid rain-fed conditions found throughout the Deccan Plateau. Summers are hot and winters are temperate. 
Musi sub-basin is subject to both south-west and north-east monsoons. The mean annual rainfall of the catchment is $760 \mathrm{~mm}$ and is unevenly spatially and temporally distributed. At present, areas within the Musi sub-basin are already facing a water shortage with allocations in the catchment not being able to meet the demand from major demand centres.

\section{CONCEPTUAL FRAMEWORK}

The broad conceptual framework of this research hinges on the integration of modelling to support decision making, using a scenario planning approach. This framework consists of two critical parts: a) Integration of all elements of the water cycle with economic outcomes, and b) integration of research outputs into an evidence based policy formulation framework which involves the key project stakeholders. A depiction of the two-dimensional integration process is shown in Figure 1.

Scenario planning is the central concept of this framework. The use of scenarios as predicting planning tools forms an essential part of the decision support framework that will inform stakeholders of the impacts of water management decisions on future water security. Van Notten (2006) defines "scenarios" as "consistent and coherent descriptions of alternative hypothetical futures that reflect different perspectives on past, present, and future developments, which can serve as a basis for action". Scenario development entails constructing an explicit story about how the future may unfold. Water adaptation scenarios for agriculture will be defined through an interactive and structured process involving project researchers and stakeholders. A group of strong and committed stakeholders will be assembled to decide which alternatives appear more plausible.

The integration of the water cycle modeling has, as its primary objective, to determine the impact of future climate change scenarios on the water cycle system. The water cycle, which includes surface and groundwater resources, is driven by two main forcing variables: climate and watershed development (land use). The hydrologic modelling component of the framework is intended to provide the water cycle responses to these two drivers. This analysis will be developed in a 2-stage process designed to describe the hydro-geology of the system, and will include a snapshot of the current state of the water cycle (water balance analysis) and the development of a surfacegroundwater integrated hydrologic modeling framework designed to incorporate climate and WSD forcing variables. The modeling assessment process is designed to evaluate a range of scientifically defensible stakeholder driven biophysical, social and economic policies, rather than seeking a single preferred (optimal) alternative. The decision on a preferred alternative

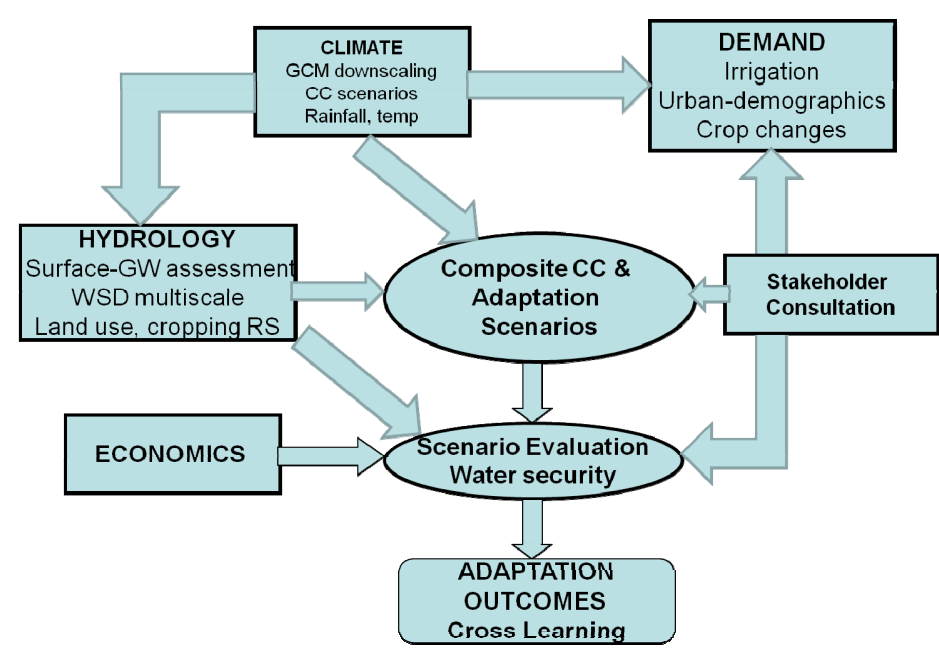

Figure 2. Conceptual Map remains with Government and other entities charged with policy formation and implementation.

Climate change and WSD will affect water demand from agriculture, urban and industrial activities and thus has an economic impact as well. This is likely to have profound impacts on the availability and security of water for agriculture. The integration of the climate change on water availability and demand will take place through a water allocation-substitution model which will allocate the resource on the basis of stakeholder driven preferences and assess the levels of security associated with each scenario. Water security in this context is represented by the combination of level of availability (quantity) and its associated security of supply (risk) for each economic activity (agriculture, urban, industrial) on a spatially distributed basis. 
George et al., A modelling framework to evaluate climate change and watershed development impacts

\subsection{Historical Climate Analysis}

Initially, an investigation of the historical changes in key climatic inputs such as temperature, relative humidity and rainfall, was undertaken in the study area. It was found that no substantial change in the southwest monsoon rainfall occurred during the last 60 years. However, over that period the number of extreme 1-day rainfall and heavy rainfall events $(>70 \mathrm{~mm} /$ day) were found to increase significantly, while low rainfall events $(2.5 \mathrm{~mm}-10 \mathrm{~mm})$ did not show a statistically significant trend. The analysis of average annual temperature shows a significant increase $\left(0.08{ }^{\circ} \mathrm{C} / \mathrm{decade}\right)$ in the Krishna basin. Hot days are increasing (but not significantly) in the central parts of the basin. Seasonal temperatures are increasing in the Krishna basin (except minimum temperatures in summer season) and a significant increase (of 5\%) has been observed in the maximum temperature series of post-monsoon season.

\subsection{Climate Modelling}

While global atmosphere-ocean coupled models have been found to adequately represent the planetary scale features of the climate, their application to regional studies is often limited by their coarse spatial resolution $(\sim 300 \mathrm{~km})$. For example, global models cannot adequately incorporate realistic topographical features like the Western Ghats along the west coast of India. As a consequence the models fail to account for the most predominant influence on the monsoon rainfall patterns over India.

The perturbed physics approach was developed in response to the call for improvements in the quantification of uncertainties in climate projections (Chapter 14 of the Third Assessment report of IPCC). The basic approach involves taking a single model structure and making perturbations to the values of parameters in the model, based on the discussions with scientists involved in the development of different parameterization schemes. In some cases, different variants of physical schemes may also be switched in and out of this process. Any number of experiments that are routinely performed with a single model can then be produced in an "ensemble mode" subject to constraints on computer time. These are known as Perturbed Physics Ensembles (PPE). A significant amount of perturbed physics experimentation has been done with the HadCM3 model and within the Quantifying Uncertainty in Model Predictions (QUMP) project at the Hadley Centre. This started with the work of Murphy et al (2004) and Stainforth et al. (2005). The QUMP global simulations, comprising 17 versions of the fully coupled version of the HadCM3 model, one with the standard parameter setting and 16 versions in which 29 of the atmosphere component parameters are simultaneously perturbed, are available.

Three simulations from a 17 member Perturbed Physics Ensemble (PPE) generated using HadCM3, have been used to drive a high resolution regional climate model PRECIS (Providing REgional Climates for Impact Studies). The PRECIS simulations, corresponding to the IPCC-SRES A1B emission scenario, are carried out for a continuous period from 1961 to 2098. PRECIS simulations were carried out at a $50 \mathrm{~km} \mathrm{x} 50$ $\mathrm{km}$ horizontal resolution over the South Asian domain. These continuous simulations for A1B scenario, provide an opportunity to assess the impact of climate change on the Indian monsoon for the three future time slices, representing the near future (i.e. 2011-2040), the medium period (i.e. 2041-2070) and the long term (i.e. 2071-2098) with implications for policy on all these time scales.

\subsection{Hydrological Assessment}

The objective of the hydrological modelling part of the project is to assess the impacts of future climate and watershed development on the catchment water cycle. The water cycle, which includes surface and groundwater resources, is driven by two main forcing variables: climate and watershed development (land use and hydrological structures). The hydrologic modelling component of the integrated modelling framework is intended to provide the water cycle responses to these drivers.

Arc SWAT has been selected as the hydrological modelling tool for individual catchments in the Basin. It is an ArcGIS - ArcView extension that has a graphical user input interface to the SWAT (Soil and Water Assessment Tool) model (see Arnold et al., 1998). The SWAT model is a process-based continuous hydrological model that can be used to assess the impacts of land use and hydrological structures on stream flows. SWAT use data on spatial variability in land use, soil and climate to capture human induced land and water management practices in a given catchment. The main model components are: climate, hydrology, erosion, plant growth, nutrients, pesticides, land management, channel and reservoir routing. For this study, the surface runoff volume will be predicted from daily rainfall using SWAT and channel routing will be carried out by using the Muskingum method. Methodologies will be established to use the remote sensing 
George et al., A modelling framework to evaluate climate change and watershed development impacts

data to determine the actual evapotranspiration rates, thus replacing the SWAT built algorithms based on the Priestly and Taylor approach to calculating the potential evaporation and the Ritchie method for determining actual evaporation.

ArcSWAT pre-processes the data for the SWAT model simulation into three different sections: a Watershed Delineation, a hydrological response unit (HRU) and a Weather Data Definition. The SWAT model divides the watershed into different sub-basins, based on the stream network. These sub-basins are further subdivided into HRU's, all which consist of homogenous land use and soil characteristics. The HRUs represent percentages of the sub basin area and are not identified spatially. In addition, there is no interaction between HRU's. Man made hydrological structures will be represented in the model as a reservoir. SWAT accommodates a single reservoir at its outlet in a sub basin. All the hydrological structures located in a sub basin will be aggregated as a single reservoir in each sub basin, using a volume-area relationship. As it is also necessary to represent the increasing volumes of all structures over time in this study, a time series of structural data were collated from Rural Development Department for this purpose. The calibration and validation of the hydrologic model will be carried out using measured stream flow data from three gauging stations.

Groundwater modelling is carried out using MODFLOW. MODFLOW is a three-dimensional block-centred finite difference, physically based model, which combines Darcy's law and the mass balance equation for calculating the subsurface flows (Harbaugh et al. 2000). It is able to represent a number of aquifer conditions, in the present study a two aquifer layer system will be taken into consideration in which first layer will be unconfined aquifer and the second layer will be confined aquifer. MODFLOW can simulate both steady and transient conditions. The model can account for all the common boundary conditions generally encountered in practice. These include a fixed or pressured heads, variable or constant fluxes, groundwater recharge/discharge, point with drawls' and drains. Several surface-subsurface interactive processes such as evaporation and river-aquifer interactions can also be adequately simulated by MODFLOW.

Remote sensing has been used to map land use, dynamic vegetation information, surface water reservoirs and evapotranspiration. This information will be integrated into the hydrologic modelling framework in order to constrain the models' parameters, to provide inputs and to calibrate and verify model outputs.

\subsection{Water Allocation Modelling}

Climate change and WSD will affect water demand from agriculture, urban and industrial activities and thus has an economic impact as well. This is likely to have profound impacts on the availability and security of water for agriculture. The integration of the climate change on water availability and demand will take place through a water allocation-substitution model which will allocate the resource on the basis of stakeholder driven preferences and assess the levels of security associated with each scenario. Water security in this context is represented by the combination of level of availability (quantity) and its associated security of supply (risk) for each economic activity (agriculture, urban, industrial) on a spatially distributed basis.

The modelling of water allocation process is based on the integration of resource availability and water demand through a network allocation model. The Resource Allocation Model (REALM), a well-proven tool to aid water resource planning and management in both urban and rural water supply systems, was used in this study to represent the system network (James et al. 1996; Perera et al. 2005). It can be applied to both urban and agricultural systems and can be used to address a diverse range of scenarios, such as sectorial water allocation, water rights, environmental flows, climate change, restrictions and supply and demand management.

The model uses a node-link network to represent the river basin where nodes represent the physical units such as reservoirs, aquifers, townships, agriculture and industries and links represents the carriers which connects the nodes (rivers, pipelines, canals etc). The nodes are of two types: source nodes and demand nodes. The source nodes represent different water sources such as surface water, reservoir, groundwater and re-use. Demand nodes include both urban and irrigation nodes. REALM uses two types of carriers: open channel type or pipe type.

The model has three input files to account for water sources, demand and description of the system (James et al. 1996). The water sources file contains information on the water flows from the headwaters of the river basin, runoff entering the source node, groundwater and climatic data. The demand file contains demand data for each demand node in the system. The system file contains the remaining information on the sources of 
water in the system (source nodes), various unrestricted demand centres, the spatial connection links and carriers and the long-term operating rules. The representation of the physical features of the system is assisted by a graphical interface facility. The model output includes information on reservoir end storage, volume supplied, unrestricted and restricted demand, spillage, shortfalls and carrier flows.

\subsection{Economic Assessment}

An economic assessment of the impacts of climate change and of strategies to curb its impacts is not easy for two reasons. First, the impacts occur over an extremely long timeframe, rendering most discounted cash flow type analyses (like Benefit Cost analysis) of limited use. Second, little is known of the uncertainties associated with climate change. These uncertainties need to be quantified (with an associated probability) before some meaning can be placed on the economic analysis. The intention in modelling the economic components of this study is to use a Real Options Analysis to identify the impacts of flexibility in response. This approach will be modified by assessing the time horizon in three distinct 30 year periods: the immediate (to 2030), intermediate (between 2030 and 2060) and infinite (2060 to 2100) periods. Within these periods water security will be assessed in conjunction with the cost effectiveness of providing a degree of water security and its concomitant impacts on net social welfare. A real challenge for the analysis is to quantify the uncertainties associated with both climate change and the measures designed to mitigate its impacts. These will be derived by putting a dynamically down scaled global climate model into the hydrological water allocation model and simulating the impacts that result.

\section{DISCUSSION AND CONCLUSIONS}

The long term impacts of climate change and WSD on water security in many river basins worldwide are expected to be considerable. Climate change and WSD are expected to have a significant impact on the hydrologic behaviour of the catchment. The Krishna river basin is closing as a result of the combined impacts of vast irrigation developments over the past 50 years and extensive WSD programs promoted by the Indian Government. The main aim of this paper is to present a methodology developed to assess the combined impacts of watershed development and climate change adaptation strategies on the long term water security for agriculture in the Krishna river basin.

The broad conceptual framework of this research hinges on the integration of modeling into a scenario planning approach to support decision making. In this research, results from a general circulation model (GCM) are downscaled to the sub-basin level to generate input forcing information adapted to run a regional hydrological model on the future climate scenarios. Initially, an investigation of the historical changes in key climatic inputs such as temperature, relative humidity and rainfall, was undertaken in the study area. Three climate simulations corresponding to the IPCC-SRES A1B scenario were downscaled for the period 19612098 using "Providing REgional Climates for Impact Studies" (PRECIS) regional climate modelling system. These simulations were based on three versions of the HadCM3 global climate model which showed realistic results for the Indian summer monsoon.

In order to assess the climate change impacts on hydrological cycle, a fully distributed surface and groundwater modelling is proposed. The impact of watershed development on hydrology will also be analysed using this modelling framework. An integrated water allocation-economic modelling will be carried out to assess the water security and its economic value. The economic components of this study will use a Real Options Analysis to identify the impacts of flexibility in response. Finally, the modelling framework will be used to evaluate a range of scientifically defensible social and economic policies driven by stakeholders.

\section{ACKNOWLEDGMENTS}

The authors acknowledge the Australian Centre for International Agricultural Research (ACIAR) for their financial support.

\section{REFERENCES}

Arnold, J.G., and Srinivasan, R. (1998). Large area hydrologic modelling and assessment Part 1: Model Development. Journal of the American Water Resources Association, 34(1): 73-89.

Arnold, J.G., and Nancy, F. (2005). SWAT2000: current capabilities and research opportunities in applied watershed modelling. Hydrological Processes, 19(3): 563-572. 
George et al., A modelling framework to evaluate climate change and watershed development impacts

Harbaugh, A.W., Banta, E.R., Hill, M.C., and McDonald, M.G. (2000). MODFLOW-2000, the U.S. Geological Survey modular ground-water model -- User guide to modularization concepts and the GroundWater Flow Process. U.S. Geological Survey Open-File Report 00-92:121

IPCC, (2007). Climate Change 2007. Fourth Assessment report on climate change. Cambridge University Press.

James, B., Kesari, N., and Hansen, W. (1996). Modeling of Capacity Shared Water Entitlements, International Hydrology and Water Resources Symposium. I.E. (Aust.), Hobart, Australia, 1996, 31-36.

Kumar, R., Sahai, A.K., Kumar, K., Patwardhan, S.K., Mishra, P.K., Revdekar, K.G., Kamala, K., and Pant, GB. (2006). High resolution climate change scenarios for India. Current science, 90(3): 334-345.

Murphy, J.M., Sexton, D.M.H., Barnett, D.N., Jones, G.S., Webb, M.J., Collins, M., and Stainforth, D.A. (2004). Quantification of modeling uncertainties in a large ensemble of climate change simulations. Nature, 430: 768-772

Perera, B.J.C., James B., and Kularathna, M.D.U. (2005). Computer software tool REALM for sustainable water allocation and management. Journal of Environmental Management, 77: 291-300.

Shah, T., Scott, C.A., Kishore, A., and Sharma, A. (2007). Energy-irrigation nexus in South India: Improving groundwater conservation and power sector viability. in "The Agricultural groundwater revolution: opportunities and threats to development" edited by Giordano and Villholth, Cab International.

Stainforth, D.A., Aina, T., Christensen, C., Collins, M., Faull, N., Frame, D. J., Kettleborough, J. A., Knight, S., Martin, A., Murphy, J. M., Piani, C., Sexton, D., Smith, L. A., Spicer, R. A., Thorpe A. J., and Allen M. R. (2005). Uncertainty in predictions of the climate response to rising levels of greenhouse gases, Nature, 433: 403-406

Van Notten, P. (2006). Chapter 4: Scenario development: A typology of Approaches. Published in Think Scenarios, Rethink Education. 